\title{
Consumption of Animal-source
} Foods in Ethiopia: Patterns, Changes, and Determinants

Getachew Ahmed Abegaz, Ibrahim Worku Hassen, and Bart Minten 


\section{TABLE OF CONTENTS}

Abstract.

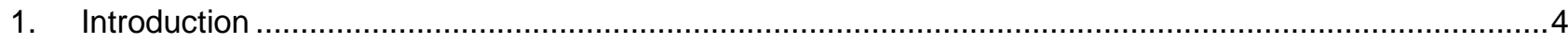

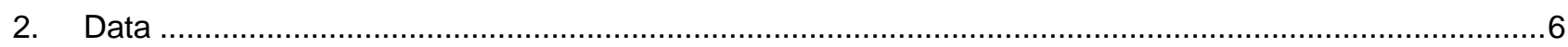

3. Patterns in Consumption of Animal-source Food and Changes over Time ..........................................

3.1. Food and animal-source food expenditures overall ..................................................................... 7

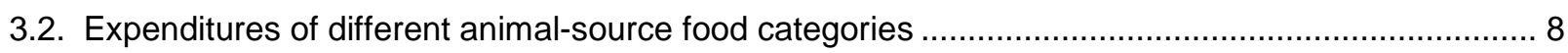

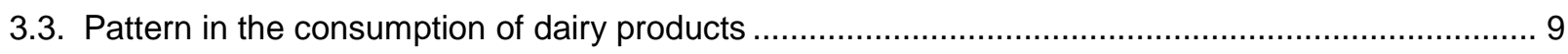

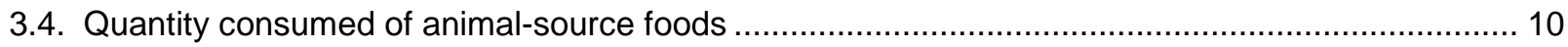

4. Regional and Rural/Urban Animal-source Food Consumption ....................................................11

5. Animal-source Food Consumption by Source of Expenditure and by Season ....................................12

5.1. Consumption of animal-source food by source of expenditure ............................................... 12

5.2. Seasonal variation in animal-source food consumption .............................................................. 13

6. The Role of Income and Prices in Animal-source Food Consumption...................................................15

6.1. Descriptives on the consumption of animal-source food by quintiles of expenditure..................... 15

6.2. Estimation method for the Quadratic Almost Ideal Demand System model ................................ 16

6.3. Results of the Quadratic Almost Ideal Demand System model................................................. 17

6.4. Simulations of future demand and of commercial market development ....................................... 19

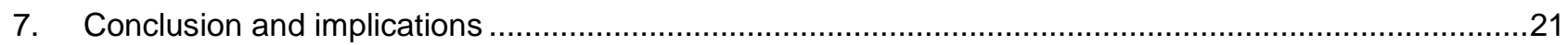

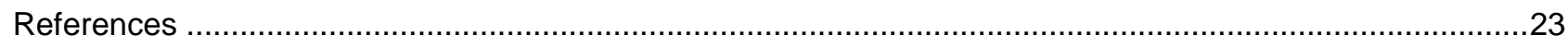

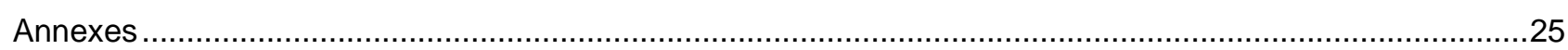

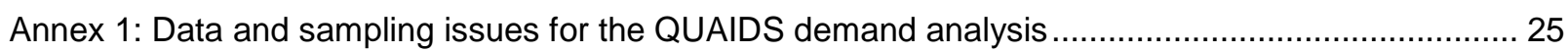

Annex 2: Animal-source food consumption and socio-economic indicators ....................................... 25

\section{LIST OF TABLES}

Table 2.1. Sample size of Household Income and Consumption Expenditure Surveys in Ethiopia, 1995/06 to

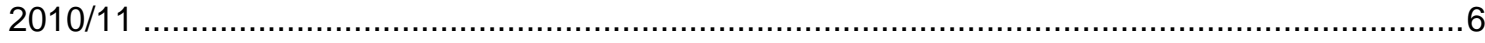

Table 3.1. Major food groups, consumption expenditure per capita and share, 1996 to 2011 ......................8

Table 3.2. Animal-source food groups, consumption expenditure per adult equivalent and budget share,

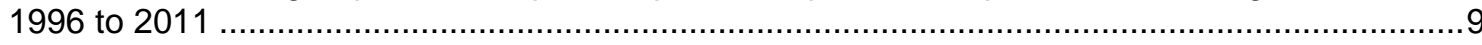

Table 3.3. Dairy products, consumption expenditure per adult equivalent and budget share, 1996 to $2011 \ldots .9$

Table 3.4. Powdered milk, consumption expenditure per adult equivalent, 1996 to 2011, ETB per year .......10

Table 3.5. Animal-source food groups, quantity consumed per adult equivalent, 2005 and 2011, kg per year

Table 4.1. Per capita consumption expenditure of animal-source food and share of animal-source food in the

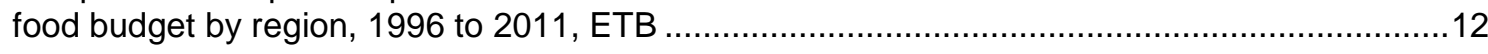

Table 4.2. Per capita consumption expenditure and share of animal-source food by residence, 1996 to 2011

Table 5.1. Consumption of animal-source food groups by source of expenditure in 2011, rural/urban, percentage share

Table 6.1. Animal-source food consumption expenditure per capita on and by food budget share, by quintiles

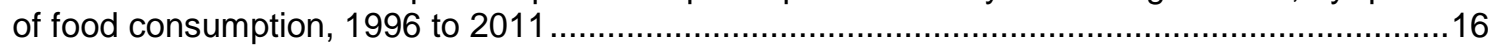

Table 6.2. Expenditure elasticities estimates for animal-source food groups .........................................17

Table 6.3. Compensated price elasticity estimates for animal-source food groups ......................................19

Table A1: Female and male-headed households, animal-source food as a percentage share of total food consumption..... 
Table A2: Employment status, animal-source food as a percentage share of total food consumption, by sex of household head

\section{LIST OF FIGURES}

Figure 3.1. International comparisions of per capita consumption of beef, poultry, and mutton, 1995 to 2010 , $\mathrm{kg}$

Figure 5.1. Seasonal variation in value of per capita consumption of animal-source food, beef, and dairy, 2011, ETB.....

Figure 5.2. Seasonal variation in value of per capita consumption of cow milk, butter, and cottage cheese, 2011, ETB

Figure 6.1. Evolution of future demand for animal-source food 20

Figure 6.2. Evolution of commercial market development for animal-source food .21 


\section{ABSTRACT}

Higher animal-source food (ASF) consumption has been shown to have important positive impacts on health and nutrition outcomes. However, patterns in consumption of ASF and drivers for those changes are not well understood in Ethiopia. Using unique nationally representative household consumption expenditure data sets that extend from 1995/96 to 2010/11, this study assesses ASF consumption patterns and changes over time. A number of stylized facts appear from this analysis:

1. While ASF consumption is low overall in Ethiopia, real expenditures on ASF have increased by 50 percent over the 15 -year period;

2. Per capita ASF consumption increased but significantly less than ASF expenditures because of relative price increases of ASF over this period;

3. Expenses on dairy products make up almost half of all ASF expenditures;

4. The share of ASF expenditures in the total food budget for the richest quintile is three times higher than for the poorest quintile;

5. Residents in urban areas spend twice as much on ASF per capita than do rural residents; and

6. There is significant variation over the year in ASF consumption, seemingly associated with religious customs.

Relying on a Quadratic Almost Ideal Demand System (QUAIDS) methodology, we further find strong effects of prices and incomes on ASF consumption levels. For example, we find that a doubling of prices reduces dairy consumption by about half. Recent hikes in prices of dairy products will likely have contributed to a decrease in consumption, but this seems to have been offset by increases in averages incomes in the country, leading to no decline in the (average) consumption of dairy products. These findings suggest overall that keeping prices low and stimulating further income increases are important factors to improve low ASF consumption in Ethiopia. Using reasonable assumptions on income growth, urbanization, prices, and marketization, we estimate that national ASF consumption and commercial markets will increase by 165 percent and 192 percent by 2030 respectively and that the size of urban commercial markets will quadruple by 2030 . Especially the goat and mutton markets are expected to increase faster than other ASF markets. This fast growth will have enormous implications for the activities of agents involved in these markets, such as input and output traders, transporters, wholesalers, retailers, butchers, and slaughterhouses.

\section{INTRODUCTION}

Ethiopia has been one of the fastest growing economies in the world in the last decade, an impressive feat for a low-income African country that exports relatively few natural resources. National official data show that real agricultural output has grown on average by 7.6 percent per year over the last decade. This growth has been a major contributor to the important reductions in poverty observed in the last decade (World Bank 2014). Agricultural growth in Ethiopia as a contributor to overall economic growth has been remarkable for Africa, which has been a laggard in agricultural performance globally (Diao, Headey, and Johnson 2008; Jayne, Anriquez, and Collier 2013). Moreover, nutritional indicators show significant improvements over this period as well. In 2000, over half of Ethiopian preschool children were stunted and almost a third were severely stunted. However, progress against child undernutrition over this period has been solid, with stunting prevalence reduced by 1.4 percent points per year between 2001 and 2011, although progress slowed to 1.0 point per year between 2011 and 2014 (Headey 2014). However, Ethiopia started from a very low base and it has still one of the most undernourished populations in the world. 
As stated in its new Growth and Transformation Plan (GTP II) for the period 2016 to 2020, the government is committed to continue on this fast growth path. Further transformation in the agricultural sector as well as nutritional improvement objectives will especially have implications on Ethiopia's livestock systems in the future. While past transformations brought about considerable improvements in calorie intake, with further transformation, livestock and ASF will have increasingly important roles to play. In line with what has been observed in other growing economies, the relative importance of cereals in total food expenditures is already decreasing in Ethiopia. We have begun to see a shift towards more preferred - but also more expensive - foods, including ASF (Worku et al. 2016). Improved livestock systems will have to cater to this increasing demand. Agriculture and livestock performance have strong synergies in these settings, so it is crucial for further agricultural growth that livestock plays its crucial complementary role (McIntire et al. 2016). As a strong link has been shown worldwide between the consumption of ASF on the one hand and improved nutritional outcomes on the other (Randolph et al. 2007; Leroy and Frongillo 2007), increasing consumption of these products in sufficient quality and quantity and at low prices is therefore desirable to achieve significantly improved nutritional status in Ethiopia (Hoddinott, Headey, and Dereje 2015; Sadler and Catley 2009). ${ }^{1}$

Given the nutritional and health benefits of ASF, studying changes and patterns in ASF consumption levels in Ethiopia and identifying the factors that might create such changes is an important endeavor. The results of such studies can inform policies to improve access to and increase consumption of ASF. ${ }^{2}$ However, the current literature lacks a good understanding of patterns in ASF consumption as well as factors that drive demand for ASF. We fill that gap in this paper. Using nationally representative data sets of four rounds of household consumption expenditure surveys that extend from 1995/96 to 2010/11, this study analyzes national ASF consumption patterns overall, across different groups of consumers, and over time. We analyze the quantities of and expenditures on ASF consumption; look at links with socio-economic indicators, disaggregated at regional levels and by the rural and urban divide; and assess the importance of income, seasonality, and commercial markets in ASF consumption. Using demand analysis based on a Quadratic Almost Ideal Demand System (QUAIDS) model, the study also assesses some of the drivers especially prices and income - on consumption and expenditures of different ASF groups.

A number of stylized facts appear from this analysis:

1. While ASF consumption is overall low, real expenditures on ASF have increased by 50 percent over the 15-year period studied;

2. ASF consumption increased less because of relative price increases of ASF;

3. Expenses on dairy products make up almost half of all the ASF expenditures;

4. The share of ASF expenditures for the richest quintile is three times higher than for the poorest quintile;

5. Residents in urban areas spend twice as much on ASF per capita than do residents in rural areas; and

6. There is significant seasonal variation in consumption, seemingly associated with religious customs.

From our demand analysis, we further find strong effects of prices and incomes on ASF consumption. For example, we find that a doubling of prices will reduce dairy consumption by half. The recent hikes in prices

\footnotetext{
${ }^{1}$ Under GTP II, the government wants to reduce stunting levels from 40 percent in 2014/15 to 26 percent in 2019/20.

2 Previous studies have suggested that increases in household incomes and reduction in the real cost of calories are important drivers for the changes in consumption levels (Tafere and Worku 2012). Furthermore, important factors that explain for the low level of ASF consumption in Ethiopia include low effective demand due to high prices (Tefera et al. 2010). Shortage of ASF, particularly milk in urban areas, is seemingly an important factor for low level of ASF consumption (Tegegne et al. 2013; Gordon, Demissie, and Tadesse 2007).
} 
of dairy products, as shown by Bachewe et al. (2017), will therefore likely have contributed to a decrease in consumption, but this seems to have been offset by increases in average incomes in the country, leading to a slight increase in the consumption of dairy products. In any case, these findings suggest more broadly that keeping prices low and stimulating further income increases will improve low ASF consumption in Ethiopia. We further simulate future demand for ASF consumption, using reasonable assumptions on urbanization and income growth, and estimate that ASF demand will increase by 165 percent by 2030. The size of the commercial markets for ASF is expected to increase even faster, being expected to almost triple by 2030 compared to 2011. This growth in commercial ASF markets will have significant implications for the services that will have to be provided in the livestock sub-sector. It will be an important challenge for Ethiopia to assure that the increased amount of ASF is delivered in safe conditions and at affordable prices.

The rest of this paper is organized as follows. In the second section, a brief description of the datasets used for the study is given. Descriptive statistics on changes and patterns of ASF consumption is provided in the third section. Section 4 then looks at consumption by region and over the urban/rural divide, while in section 5 , a discussion is presented on seasonal variation and commercial markets. We present in Section 6 the results on the analysis of prices and income using descriptive analysis as well as the results from the use of a QUAIDS model. We use these estimates to assess possible future scenarios of ASF consumption and market development. Finally in Section 7, we finish with our conclusions.

\section{DATA}

For our analysis, we use nationally representative household income and consumption expenditure surveys (HICES) conducted by the Central Statistics Agency (CSA) of the government of Ethiopia. These surveys were conducted in 1995/96, 1999/00, 2004/05, and 2010/11 (CSA 1998, 2001, 2007, 2012a). The surveys have household consumption and expenditure information by food item and income, except for the 2010/11 survey which only has expenditure modules. Additional information on household characteristics and asset holdings that is needed for the demand analysis were taken from welfare monitoring surveys (CSA 2012c, 2012b). The HICES are repeated cross-sectional surveys collected by the Central Statistical Agency (CSA) and serve as the official source for poverty statistics in Ethiopia (MoFED 2013). The sampling was done by stratifying the country into rural and urban areas. After that, enumeration areas were selected using a probability proportional to size approach where more populated units had a higher probability of being selected into the final sample. We use sampling weights provided by the CSA, which are based on selection probabilities, to compute representative estimates for rural and urban areas of the country.

Except for the 2004/05 survey, which excluded all zones of Gambella, three zones in Afar, and six zones in Somali regions (predominantly the non-sedentary zones in Afar and Somali), the surveys were conducted in all regions and zones of the country. The sample size of the four surveys is given in Table 2.1.

Table 2.1. Sample size of Household Income and Consumption Expenditure Surveys in Ethiopia, $1995 / 06$ to $2010 / 11$

\begin{tabular}{ccrr}
\hline & \multicolumn{3}{c}{ Number of households } \\
Year & Total & \multicolumn{1}{c}{ Rural } & \multicolumn{1}{c}{ Urban } \\
\hline $1995 / 96$ & 11,928 & 7,171 & 4,757 \\
$1999 / 00$ & 17,332 & 8,660 & 8,672 \\
$2004 / 05$ & 21,595 & 9,494 & 12,101 \\
$2010 / 11$ & 27,834 & 10,321 & 17,513 \\
\hline
\end{tabular}

Source: CSA, HICE Survey reports 
In principle, CSA defines urban areas as a locality with 2,000 or more inhabitants. However, for practical purposes, it does not strictly follow this definition while conducting these surveys. For the 1995/96 and 1999/00 surveys, urban centers included (a) all administrative capitals, i.e., regional, zonal and woreda capitals, (b) localities with urban dwellers associations, and (c) all localities which are not included either in (a) or (b) above having a population of 1,000 or more persons engaged in non-agricultural activities. Areas not in (a), (b), or (c) were considered to be rural. For the 2004/05 and 2010/11 surveys, CSA divided the country into three broad categories: rural, major urban, and other urban centers. The rural category consists of all rural areas in all regions of the country, except Gambella region, three zones in the Afar, and six zones in the Somali regions that were not surveyed. Major urban consists mainly of regional capitals and other urban centers with relatively sizable population. Other urban centers include all urban areas that do not fall under the major urban centers category.

To make total and ASF consumption expenditures comparable over time, real values of consumption expenditures were computed based on 1995/96 prices using CSA's national consumer price index of the respective years of the survey. It is to be noted that due to differences in cleaning methods, the results presented in this paper have minor differences from other analyses, such as Tafere and Worku (2012) and Worku et al. (2016). For the econometric analysis, in addition to HICES, we used data from the Welfare Monitoring Surveys (WMS) and retail price surveys collected by CSA. We briefly highlight in Annex 1 some of the changes in the 2011 data structure that could have a bearing on the estimated elasticity coefficients.

Some notes of caution with the use of these data and with its interpretation are required.

- There might be comparability issues with consumption data using a recall report of "over the last 7 days". Such data would ideally have been collected in the same week for the whole sample, since data collected during weeks in which religious festivals are celebrated and normal week might differ substantially, even for the same household.

- There was a change in the data collection period between the 1996, 2000, and 2005 surveys, which were conducted in two relative short periods after the main meher harvest (January and February) and in the lean period (July and August), respectively, and the 2011 survey, which was conducted over the course of the full year. Stifel and Woldehanna (2014) test the impact of this change in periods by limiting the sample to those sample households in the 2011 survey that were interviewed in the same months as in the previous surveys, and they do not detect a significant difference when compared with the whole sample for the 2011 survey.

- The food codes used changed over the period considered, especially between 2000 and the two latter surveys.

- As there is no panel component to the repeated cross-sectional survey set-up, this limits the techniques as well as the controls that can be used in dynamic analysis.

\section{PATTERNS IN CONSUMPTION OF ANIMAL-SOURCE FOOD AND CHANGES OVER TIME}

\subsection{Food and animal-source food expenditures overall}

We start by putting the consumption of ASF in the context of the entire food consumption basket. Table 3.1 shows the evolution of overall food expenditures by broad food categories, including ASF. A number of important patterns can be seen. 
Table 3.1. Major food groups, consumption expenditure per capita and share, 1996 to 2011

\begin{tabular}{lrrrr|rrrr}
\hline & $\mathbf{1 9 9 6}$ & $\mathbf{2 0 0 0}$ & $\mathbf{2 0 0 5}$ & $\mathbf{2 0 1 1}$ & $\mathbf{1 9 9 6}$ & $\mathbf{2 0 0 0}$ & $\mathbf{2 0 0 5}$ & $\mathbf{2 0 1 1}$ \\
\hline & \multicolumn{3}{c|}{ Per capita food expenditures } \\
& \multicolumn{3}{c|}{ (ETB per year) } & \multicolumn{3}{c}{$\begin{array}{c}\text { Share of food basket } \\
\text { (\%) }\end{array}$} \\
\hline Teff & 89.2 & 96.2 & 72.7 & 68.6 & 12.4 & 12.5 & 9.2 & 7.4 \\
Wheat & 54.0 & 66.6 & 73.3 & 67.5 & 7.5 & 8.6 & 9.2 & 7.3 \\
Barley & 3.9 & 28.7 & 37.3 & 21.9 & 4.7 & 3.7 & 4.7 & 2.4 \\
Maize & 75.0 & 88.5 & 72.0 & 67.6 & 10.4 & 11.5 & 9.1 & 7.3 \\
Sorghum & 53.8 & 46.4 & 66.8 & 45.8 & 7.5 & 6.0 & 8.4 & 4.9 \\
Other cereals, pulses \& oilseeds & 100.0 & 107.0 & 94.7 & 144.5 & 13.9 & 13.9 & 11.9 & 15.6 \\
Animal products * & 69.8 & 70.0 & 85.1 & 104.4 & 9.7 & 9.1 & 10.7 & 11.2 \\
Vegetables (incl. pepper), fruits, & 78.3 & 148.1 & 102.6 & 166.6 & 10.9 & 19.3 & 12.9 & 17.9 \\
$\quad$ root crops (incl. enset/kocho) & & & & & & & & \\
Other foods & 164.4 & 118 & 189.2 & 241.7 & 22.9 & 15.3 & 23.8 & 26.0 \\
\hline Total food basket & 718.3 & 769.4 & 793.8 & 928.6 & 100.0 & 100.0 & 100.0 & 100.0 \\
\hline
\end{tabular}

Source: Authors' calculation based on HICE, CSA

Note: * The per capita figures for animal products is a little higher than figures in previous reports, such as Hassen et al. (2016) and Tafere and Worku (2012), as those reports categorized butter under the Fats and Oils food items. Because butter is an important dairy product (see Table 6.3) second only to liquid milk, it is categorized under the animal products category for this study.

First, expenditures on food consumption have been increasing over the 15-year period studied by almost 30 percent. This is partly driven by increases in actual quantities consumed but also by a change in the types of foods eaten, especially a relative shift away from cereals to more expensive foods (for more detail, see Worku et al. (2016)). In particular, consumption of ASF in the Ethiopian diets is rapidly increasing. Real annual per capita consumption expenditure on ASF was ETB 70 in 1996 in real terms. This increased to ETB 104 in 2010/11, a growth of 50 percent. This growth was significantly higher than the growth in overall food expenditures. These patterns are a reflection of Bennett's (1941) law that describes a relative decline in starchy staples and an increase in animal proteins with an increase in income.

Second, Table 3.1 shows the relative importance of different food categories in the total food basket. It shows that ASF consumption in the overall food basket is still relatively low, at 11.2 percent in 2011 (see Humphries et al. (2014) for a comparison with Peru). Given the faster increases of real expenditures in ASF compared to food overall, Table 3.1 shows that the share of ASF in total food expenditure has been increasing over the 1996 to 2011 period from 9.7 percent in 1995/96 to 11.2 percent in 2010/11, so that by 2011 ASF expenditures were on average higher than those for the most important cereal in the food basket, teff.

\subsection{Expenditures of different animal-source food categories}

ASF covers a large amalgam of animal products. In this section, we split overall ASF consumption expenditures into different categories (Table 3.2). Several patterns of note can be seen.

Only a few types of ASF dominate the consumption of the average Ethiopian, mainly dairy products in the form of liquid cow milk, butter, cottage cheese, and butter milk (arera), beef, mutton and goat, and chicken and eggs. This reflects the livestock production system in the country, where the livestock population is dominated by cattle (including cows), sheep and goats, and poultry (CSA 2016). Pork, which is rarely eaten in Ethiopia due to religious customs, along with camel, fish, and honey do not make up a significant share of the Ethiopian diet. 
Table 3.2. Animal-source food groups, consumption expenditure per adult equivalent and budget share, 1996 to 2011

\begin{tabular}{lrrrr|rrrr}
\hline & 1996 & $\mathbf{2 0 0 0}$ & $\mathbf{2 0 0 5}$ & $\mathbf{2 0 1 1}$ & $\mathbf{1 9 9 6}$ & $\mathbf{2 0 0 0}$ & $\mathbf{2 0 0 5}$ & $\mathbf{2 0 1 1}$ \\
\hline & \multicolumn{3}{c}{$\begin{array}{c}\text { Per capita ASF expenditures } \\
\text { (ETB per year) }\end{array}$} & \multicolumn{3}{c}{ Share of animal-source foods } \\
Beef & 16.9 & 23.4 & 27.2 & 33.3 & 24.4 & 33.4 & 31.7 & 31.9 \\
Mutton \& goat & 5.1 & 10.5 & 10.6 & 12.8 & 7.3 & 15.0 & 12.3 & 12.3 \\
Chicken & 2.6 & 2.1 & 3.8 & 4.9 & 3.7 & 3.0 & 4.4 & 4.7 \\
Other meat & 0.2 & 0.2 & 0.1 & 0.0 & 0.3 & 0.3 & 0.1 & 0.0 \\
Fish products & 0.4 & 0.4 & 0.3 & 0.6 & 0.5 & 0.6 & 0.3 & 0.5 \\
Dairy products & 42.7 & 29.6 & 41.2 & 49.3 & 61.6 & 42.3 & 48.1 & 47.3 \\
Eggs & 1.2 & 3.4 & 1.3 & 2.2 & 1.7 & 4.9 & 1.5 & 2.1 \\
Honey & 0.4 & 0.3 & 1.3 & 1.3 & 0.5 & 0.4 & 1.5 & 1.2 \\
\hline Total animal-source food & 69.4 & 70.0 & 85.7 & 104.4 & 100.0 & 100.0 & 100.0 & 100.0 \\
\hline
\end{tabular}

Source: Authors' calculation based on HICE, CSA

Beef and dairy products are the most important ASF groups consumed in the country. Both of them have shown high growth in consumption between 1995/96 and 2010/11. However, mutton and goat and poultry products, i.e., chicken and eggs, are becoming more important over time, but their consumption levels are starting from a low base. Per capita consumption for these ASF groups doubled between 1996 and 2011.

\subsection{Pattern in the consumption of dairy products}

Dairy products are the most important ASF, as almost half of all expenditures on ASF was for the consumption of these products in 2010/11. Moreover, per capita consumption of dairy products has been rapidly increasing, from ETB 30 in 1999/00 to ETB 49 in 2010/11 (consumption was also high in 1996, but it is not clear why consumption dropped so steeply by 1999/00). Given the importance of dairy products in ASF consumption, we present more details on the different items in this category in Table 3.3. Cow milk constituted 45 percent of total consumption of dairy products in 2011. Butter made up an important budget share as well at 30 percent.

Table 3.3. Dairy products, consumption expenditure per adult equivalent and budget share, 1996 to 2011

\begin{tabular}{lcccc|ccrr}
\hline & 1996 & $\mathbf{2 0 0 0}$ & $\mathbf{2 0 0 5}$ & $\mathbf{2 0 1 1}$ & $\mathbf{1 9 9 6}$ & $\mathbf{2 0 0 0}$ & $\mathbf{2 0 0 5}$ & $\mathbf{2 0 1 1}$ \\
\hline & \multicolumn{3}{c}{$\begin{array}{c}\text { Per capita food expenditures } \\
\text { (ETB per year) }\end{array}$} & \multicolumn{3}{c}{$\begin{array}{c}\text { Share of dairy products } \\
\text { (\%) }\end{array}$} \\
\hline Cow milk & 20.5 & 13.0 & 19.4 & 22.3 & 48.0 & 43.8 & 47.1 & 45.1 \\
Camel milk & - & - & - & 0.3 & - & - & - & 0.6 \\
Goat milk & - & - & 0.0 & 0.7 & - & - & 0.1 & 1.4 \\
Sheep milk & - & - & - & 0.2 & - & - & - & 0.3 \\
Powdered milk & 0.2 & 0.3 & 0.4 & 0.5 & 0.4 & 0.9 & 1.1 & 1.1 \\
Yoghurt & 0.7 & 0.9 & 1.4 & 2.1 & 1.6 & 3.0 & 3.5 & 4.3 \\
Cottage cheese & 3.0 & 2.4 & 3.3 & 4.6 & 7.0 & 8.3 & 8.1 & 9.2 \\
Whey (aguat) & - & - & 0.5 & 0.3 & - & - & 1.1 & 0.6 \\
Butter milk (arera) & 5.1 & 5.0 & 4.5 & 3.6 & 12.0 & 16.7 & 11.0 & 7.2 \\
Butter & 13.2 & 8.1 & 11.6 & 14.9 & 30.8 & 27.3 & 28.1 & 30.1 \\
\hline Total dairy & 42.7 & 29.6 & 41.2 & 49.3 & 100.0 & 100.0 & 100.0 & 100.0 \\
\hline
\end{tabular}

Source: Authors' calculation based on HICE, CSA

Given the increasing importance of powdered milk imported into Ethiopia, we examine this item in more detail. We note that expenditures on powdered milk have more than doubled in the last 15 years (Table 3.4). This seems driven by high consumption levels in urban areas where expenditure levels on powdered 
milk were on average six times higher than in rural areas in 2011. We also see surprising high level of consumption in the pastoralist areas of Afar and Somali. Milk is traditionally a main consumption item in the food basket of pastoralists, and it seems that there is an important part of this population that relies on imported powdered milk to fulfill that demand.

Table 3.4. Powdered milk, consumption expenditure per adult equivalent, 1996 to 2011, ETB per year

\begin{tabular}{lcccc}
\hline & $\mathbf{1 9 9 6}$ & $\mathbf{2 0 0 0}$ & $\mathbf{2 0 0 5}$ & $\mathbf{2 0 1 1}$ \\
\hline National & 0.2 & 0.3 & 0.4 & 0.5 \\
\hline Urban & 0.7 & 0.6 & 1.5 & 1.9 \\
Rural & 0.1 & 0.2 & 0.3 & 0.3 \\
\hline By region & & & & \\
$\quad$ Tigray & 0.1 & 0.2 & 0.2 & 0.3 \\
Afar & 2.1 & 0.8 & 6.8 & 6.1 \\
Amhara & 0.1 & 0.0 & 0.1 & 0.1 \\
Oromia & 0.3 & 0.3 & 0.6 & 0.3 \\
Somali & & 5.6 & 1.7 & 5.0 \\
Benishangul-Gumuz & 0.0 & 0.3 & 0.3 & 0.3 \\
SNNP & 0.0 & 0.1 & 0.2 & 0.2 \\
Gambella & 0.0 & 0.1 & & 0.1 \\
Harari & 0.1 & 1.0 & 3.9 & 0.1 \\
Addis Ababa & 1.3 & 0.5 & 1.9 & 4.2 \\
Dire Dawa & 0.6 & 1.6 & 4.2 & 5.4 \\
\hline
\end{tabular}

Source: Authors' calculation based on HICE, CSA

Note: SNNP = Southern Nations, Nationalities, and Peoples' Region

\subsection{Quantity consumed of animal-source foods}

We further look at the actual quantities consumed of ASF. While expenditures on ASF grew by 22 percent between 2005 and 2011, the quantities of ASF consumed grew much more slowly. Table 3.5 shows that the quantities consumed only increased by 6 percent over the same period, i.e., annual mean consumption per adult equivalent of ASF was $19.5 \mathrm{~kg}$ in 2005, and this increased to $20.6 \mathrm{~kg}$ in 2011 . This slower rate of growth illustrates the increasing costs of ASF over time (Bachewe et al. 2017). In terms of the quantity of ASF consumed, the most important ASF is dairy products, as was the case for expenditures. However, overall, the quantity of dairy products consumed did not change between 2005 and 2011.

Table 3.5. Animal-source food groups, quantity consumed per adult equivalent, 2005 and 2011, kg per year

\begin{tabular}{lcr}
\hline \multicolumn{1}{c}{ ASF group } & $\mathbf{2 0 0 5}$ & $\mathbf{2 0 1 1}$ \\
\hline Beef & 2.5 & 3.2 \\
Mutton \& goat & 1.3 & 1.3 \\
Chicken & 0.5 & 0.5 \\
Other meat & 0.0 & 0.0 \\
Fish products & 0.1 & 0.2 \\
Dairy products & 14.7 & 14.7 \\
Eggs & 0.0 & 0.3 \\
Honey & 0.4 & 0.5 \\
\hline Total animal- & 19.5 & 20.6 \\
$\quad$ source food & & \\
\hline
\end{tabular}

Source: Authors' calculation based on HICE, CSA 
To put these ASF consumption numbers from Ethiopia into an international perspective, we rely on data from the Food and Agriculture Organization (FAO). As the FAO uses different analytical methods, their estimates in the case of Ethiopia are slightly different from our estimates, but they are in the same order of magnitude. Figure 3.1 compares consumption of ASF in Ethiopia with the world (WLD), sub-Saharan Africa (SSA), and the high and middle-income countries that make up the Organisation for Economic Co-operation and Development (OECD). The figure illustrates that consumption in Ethiopia is low compared with the rest of the world. However, while consumption of beef is similar with sub-Saharan countries, consumption of mutton and poultry is significantly lower. Specifically for poultry consumption, unlike elsewhere, where per capita consumption of poultry has been increasing over this period, the average quantity of poultry consumed in Ethiopia has been constant for the period 1995 to 2010.

Figure 3.1. International comparisions of per capita consumption of beef, poultry, and mutton, 1995 to $2010, \mathrm{~kg}$

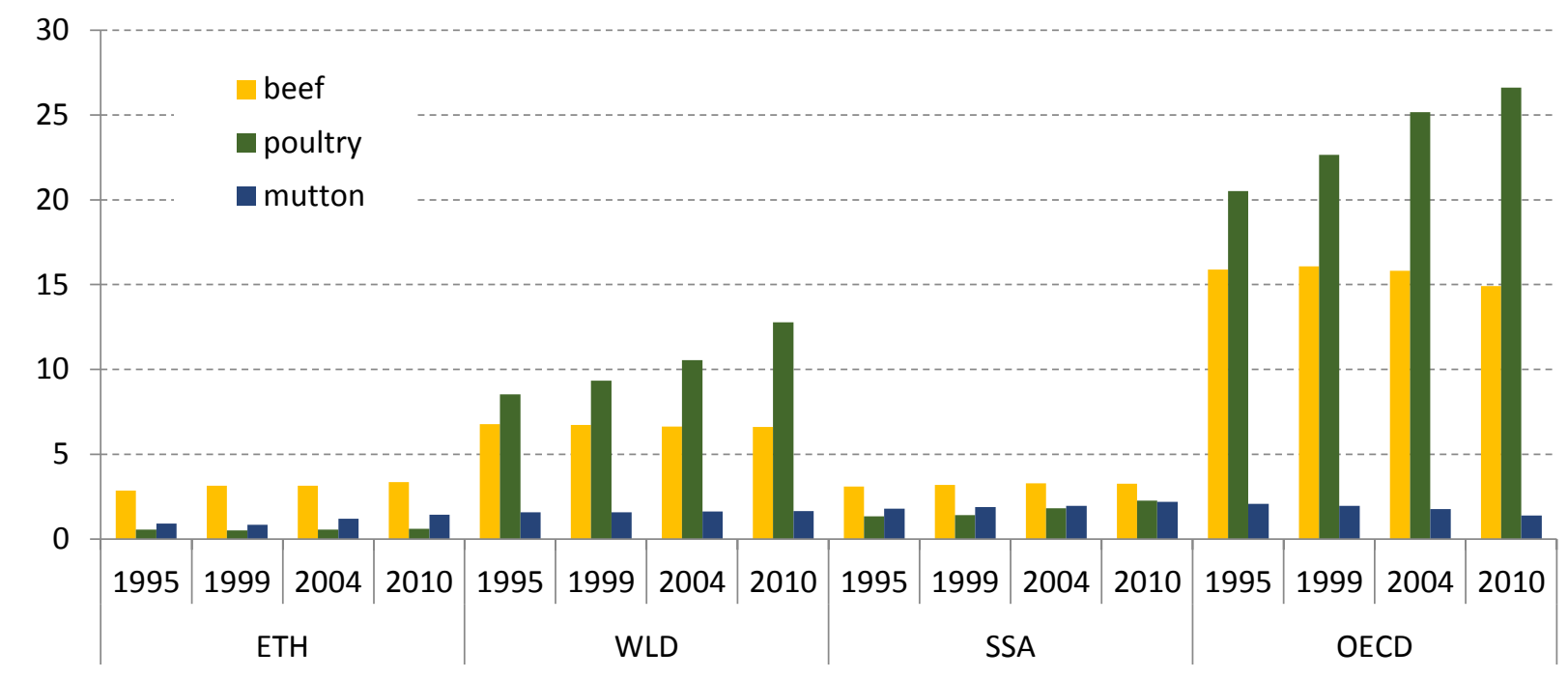

Source: OECD-FAO Agricultural Outlook (Edition 2016), (FAO 2016)

Note: $\mathrm{ETH}=$ Ethiopia; $\mathrm{WLD}=$ world; SSA = sub-Saharan Africa; OECD = Organisation for Economic Co-operation and Development

\section{REGIONAL AND RURAL/URBAN ANIMAL-SOURCE FOOD CONSUMPTION}

We next look at consumption patterns by region and by rural/urban. First, per capita consumption expenditures on ASF in Afar, Somali, Gambella, Harari, and Addis Ababa are higher than for the other regions (Table 4.1). The larger per capita expenditures in Afar and Somali can partly be explained by the fact that the production system and the livelihood of farmers in these areas are mainly dependent on livestock, as a large share of residents in these areas are pastoralists. Per capita consumption in urban areas, such as Addis Ababa and Dire Dawa, is also shown to be higher, seemingly linked with income differences and associated resulting changes in household preferences. 
Table 4.1. Per capita consumption expenditure of animal-source food and share of animal-source food in the food budget by region, 1996 to 2011, ETB

\begin{tabular}{lrrrr|rrrr}
\hline & $\mathbf{1 9 9 6}$ & $\mathbf{2 0 0 0}$ & $\mathbf{2 0 0 5}$ & $\mathbf{2 0 1 1}$ & $\mathbf{1 9 9 6}$ & $\mathbf{2 0 0 0}$ & $\mathbf{2 0 0 5}$ & $\mathbf{2 0 1 1}$ \\
\hline & \multicolumn{1}{c}{ Per capita } & ASF & expenditures (ETB) & \multicolumn{2}{c}{ Share of ASF in food budget (\%) } \\
\hline Tigray & 29.2 & 59.2 & 84.2 & 103.8 & 4.2 & 7.4 & 11.6 & 10.4 \\
Afar & 114.6 & 192.7 & 226.1 & 252.8 & 10.2 & 23.8 & 25.8 & 23.0 \\
Amhara & 26.2 & 53.3 & 52.6 & 74.9 & 4.0 & 6.7 & 7.3 & 7.9 \\
Oromia & 95.0 & 76.7 & 97.9 & 103.6 & 12.3 & 9.9 & 11.3 & 11.4 \\
Somali & 149.5 & 156.8 & 153.0 & 186.0 & 15.7 & 17.2 & 17.2 & 16.5 \\
Benishangul-Gumuz & 66.7 & 93.5 & 93.4 & 102.2 & 9.2 & 13.2 & 10.4 & 10.8 \\
SNNP & 69.6 & 59.7 & 85.0 & 103.9 & 11.7 & 9.0 & 11.3 & 13.2 \\
Gambella & 210.1 & 132.6 & $n / a$ & 230.5 & 22.0 & 17.7 & $n / a$ & 21.0 \\
Harari & 159.3 & 107.5 & 125.0 & 170.4 & 12.8 & 9.9 & 11.7 & 12.1 \\
Addis Ababa & 164.3 & 141.3 & 135.7 & 225.7 & 13.9 & 13.7 & 17.0 & 15.6 \\
Dire Dawa & 114.4 & 107.2 & 93.8 & 106.8 & 11.4 & 9.6 & 10.2 & 8.6 \\
\hline Total & 69.8 & 70.0 & 85.1 & 104.4 & 9.7 & 9.1 & 10.7 & 11.2 \\
\hline
\end{tabular}

Source: Authors' calculation based on HICE, CSA

Note: SNNP = Southern Nations, Nationalities, and Peoples' Region

Second, we compare consumption levels of rural versus urban areas, finding strong differences (Table 4.2). Per capita consumption of ASF in urban areas is much higher than in rural areas, almost twice as high. Consumption increased between 1996 and 2011 in both areas, however. In 1995/96, per capita consumption was ETB 126.8 in urban areas versus ETB 60.6 in rural areas. This wedge continued into 2010/11 when urban residents consumed on average ETB 177.1 and rural residents ETB 89.9. For a more detailed discussion of the link between ASF consumption and socio-economic indicators, see Annex 2 .

Table 4.2. Per capita consumption expenditure and share of animal-source food by residence, 1996 to 2011

\begin{tabular}{|c|c|c|c|c|}
\hline & 1996 & 2000 & 2005 & 2011 \\
\hline \multicolumn{5}{|c|}{ Per capita expenditure on ASF, ETB } \\
\hline urban & 126.8 & 121.3 & 138.3 & 177.1 \\
\hline rural & 60.6 & 62.0 & 76.3 & 89.9 \\
\hline \multicolumn{5}{|c|}{ ASF expenditure as share of total food, \% } \\
\hline urban & 13.0 & 13.8 & 16.0 & 13.6 \\
\hline rural & 8.9 & 8.2 & 9.8 & 10.5 \\
\hline total & 9.7 & 9.1 & 10.7 & 11.2 \\
\hline
\end{tabular}

Source: Authors' calculation based on HICE, CSA

\section{ANIMAL-SOURCE FOOD CONSUMPTION BY SOURCE OF EXPENDITURE AND BY SEASON}

\subsection{Consumption of animal-source food by source of expenditure}

In the 2011 survey, questions were asked on the financing of expenditures on ASF, allowing for three possibilities - own production; financed from farm income; or financed from other income sources. Some distinctive patterns show up that have been observed by other authors (e.g., Sibhatu and Qaim 2017). Table 5.1 shows that at the national level, 39 percent of consumption of ASF comes from own production. This suggests that ASF markets are already relatively important overall since almost two-thirds of ASF consumption is acquired from the market. We also see an important difference between urban and rural areas. In urban areas, a large majority of overall ASF consumption, i.e. 95 percent, is obtained from 
purchases. In rural areas, consumption from own production is much more important, i.e., an estimated 52 percent.

There are important differences in the source of expenditures by type of ASF, however. In rural areas, almost 80 percent of dairy products are obtained from own production, with few households relying on purchases to obtain these products. Given the importance of dairy products for nutritional outcomes, this confirms the results of other researchers that show that having cows is a way to improve nutritional outcomes of household members, especially so in remote areas where dairy markets are often missing (Hoddinott, Headey, and Dereje 2015). At the other extreme, beef meat is mostly obtained through purchases, with few households obtaining beef from their own cattle.

Table 5.1. Consumption of animal-source food groups by source of expenditure in 2011, rural/urban, percentage share

\begin{tabular}{|c|c|c|c|c|c|c|c|c|c|}
\hline \multirow[t]{2}{*}{ ASF group } & \multicolumn{3}{|c|}{ Urban } & \multicolumn{3}{|c|}{ Rural } & \multicolumn{3}{|c|}{ Ethiopia } \\
\hline & $\begin{array}{c}\text { Own } \\
\text { produc- } \\
\text { tion }\end{array}$ & $\begin{array}{l}\text { Purchas- } \\
\text { ed using } \\
\text { farm } \\
\text { income }\end{array}$ & $\begin{array}{l}\text { Purchas- } \\
\text { ed using } \\
\text { other } \\
\text { income } \\
\text { sources }\end{array}$ & $\begin{array}{l}\text { Own } \\
\text { produc- } \\
\text { tion }\end{array}$ & $\begin{array}{l}\text { Purchas- } \\
\text { ed using } \\
\text { farm } \\
\text { income }\end{array}$ & $\begin{array}{l}\text { Purchas- } \\
\text { ed using } \\
\text { other } \\
\text { income } \\
\text { sources }\end{array}$ & $\begin{array}{c}\text { Own } \\
\text { produc- } \\
\text { tion }\end{array}$ & $\begin{array}{l}\text { Purchas- } \\
\text { ed using } \\
\text { farm } \\
\text { income }\end{array}$ & $\begin{array}{c}\text { Purchas- } \\
\text { ed using } \\
\text { other } \\
\text { income } \\
\text { sources }\end{array}$ \\
\hline Beef & 0.1 & 4.1 & 95.9 & 2.2 & 57.9 & 39.9 & 1.4 & 37.3 & 61.3 \\
\hline Mutton \& goat & 1.1 & 7.3 & 91.6 & 38.6 & 45.1 & 16.3 & 23.7 & 30.1 & 46.2 \\
\hline Chicken & 6.3 & 4.5 & 89.2 & 58.6 & 25.0 & 16.4 & 37.4 & 16.7 & 45.9 \\
\hline Other meat & - & 4.3 & 95.7 & - & 38.3 & 61.7 & - & 15.9 & 84.1 \\
\hline Fish products & - & 9.3 & 90.7 & 4.6 & 17.0 & 78.4 & 3.1 & 14.6 & 82.3 \\
\hline Dairy products & 14.5 & 2.8 & 82.8 & 79.9 & 11.7 & 8.4 & 69.4 & 10.2 & 20.3 \\
\hline Eggs & 6.9 & 1.3 & 91.8 & 62.2 & 15.3 & 22.4 & 30.5 & 7.3 & 62.2 \\
\hline Honey & 10.0 & 1.6 & 88.4 & 25.8 & 50.0 & 24.2 & 23.2 & 41.9 & 34.9 \\
\hline Total ASF & 4.9 & 4.2 & 90.9 & 52.2 & 28.9 & 18.9 & 38.9 & 22.0 & 39.2 \\
\hline
\end{tabular}

Source: Authors' calculation based on HICE, CSA

\subsection{Seasonal variation in animal-source food consumption}

Seasonality in agricultural production and in the supply of agricultural commodities, including ASF, is due to climatic and, most importantly, rainfall patterns. Rainfall in Ethiopia is unimodal in the west and north of the country with rainfall mostly falling between June and September and one main crop harvest (meher), while it is bi-modal in the east and southeast of the country, giving rise to a second season $(b e l g)$ in those areas. Moreover, rainfall is more reliable in the west and south of the country than in other parts. As the production of feed for livestock is linked to this rainfall pattern, it induces seasonal patterns in the livestock sector. Farmer (2010) shows that seasonality is an important factor in the livelihoods of pastoralist households as rangelands can support fewer animals during the dry season, leading owners to sell livestock during the dry season or migrate to areas with better feed availability, while holding on to livestock during the wet season. For farmers in the highlands, fewer sales of livestock occur during the rainy period as feed is more easily available and cattle are needed for crop cultivation. These factors lead to significant seasonality in ASF prices (Bachewe et al. 2017).

We also note significant seasonality in ASF consumption. One important characteristic of ASF consumption, particularly in Ethiopia, is its link with religion. An estimated 43 percent of the population are Orthodox Christians (CSA 2009) and their religion is characterized by important constraints on food intake, especially related to ASF. Figure 5.1 shows how consumption expenditures on ASF vary over the course of the year. We see peaks in the beginning of the year associated with Ethiopian Christmas and Timket holy days, in 
April for Easter, and in September for the Ethiopian New Year and the Meskel holy day. These consumption peaks associated with major religious events are preceded by troughs, which are linked with fasting periods that come before these festivals. This is especially so for Christmas and Easter. During the fasting periods of Orthodox Christians - the fasting period for Lent leading-up to Easter lasts up to 56 days and the one before Christmas for about 40 days - no ASF are consumed by most practicing Orthodox Christians. While there are other fasting periods during the year, they are much shorter. ${ }^{3}$ This reduction in consumption of ASF also shows up in slaughterhouse data in Addis Ababa. The number of head of cattle and of sheep and goats slaughtered in the "Christian hall" of the slaughterhouse in the month before Easter typically drops to onequarter the level of other months (FVI-Idele 2016). No such seasonality is seen for the "Muslim hall" during the Muslim major fasting season of Ramadan, and there is no evidence of higher activity at the end of Ramadan or for the Eid festivities.

Figure 5.1. Seasonal variation in value of per capita consumption of animal-source food, beef, and dairy, 2011, ETB

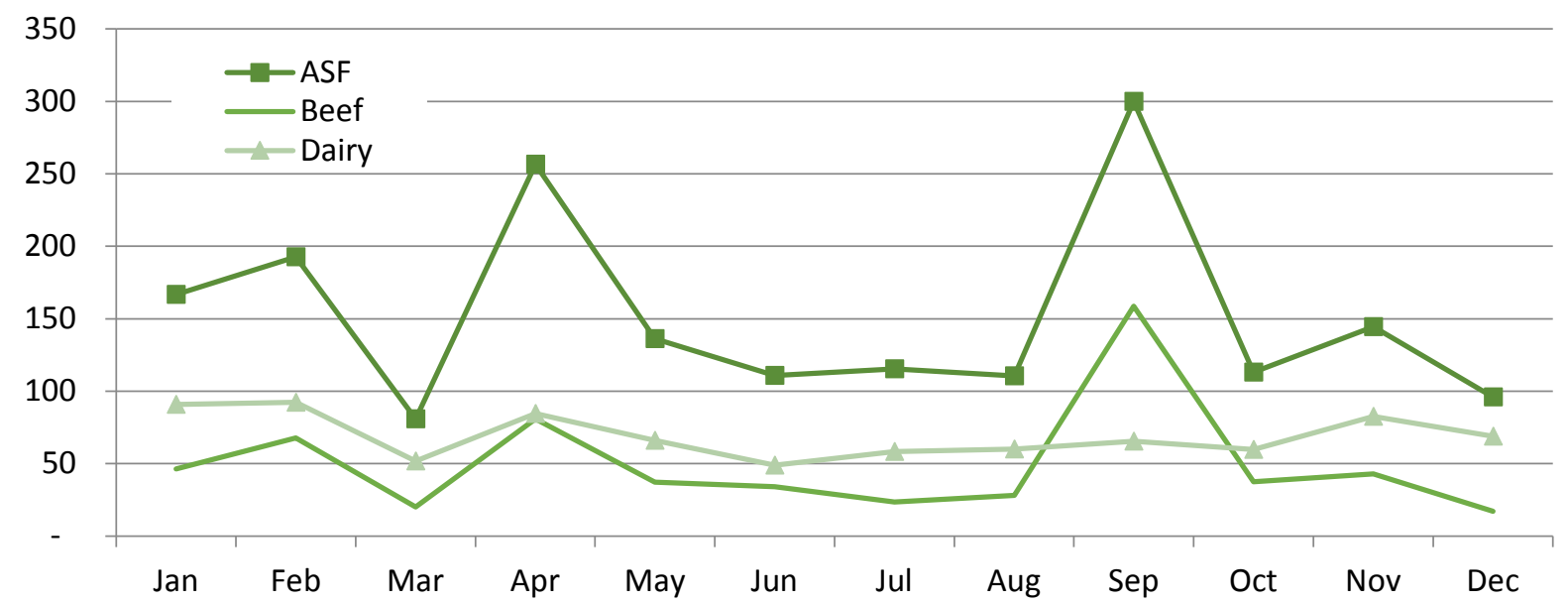

Source: Authors' calculation based on HICE, CSA

In Figure 5.1, dairy products show much less seasonal variation than do meat products. However, looking into the major components of dairy products (Figure 5.2), butter shows similar variation to total ASF and beef consumption partly because it is complementary to consumption of other ASF items such as beef, as it is usually used to cook these food items. Overall, these results show that the religious customs and fasting patterns observed in Ethiopia have a major bearing on consumption levels of ASF.

\footnotetext{
${ }^{3}$ On top of these long fasting periods, Orthodox Christians also do not eat ASF on Wednesday and Friday. It has been estimated that the total number of days that clergy (i.e. priest, nuns, monks) are not allowed to eat ASF amounts to 250 per year (Ayenew et al. 2009). For non-clergy practicing Orthodox Christians, the number of fasting days amounts to between 166 and 180.
} 
Figure 5.2. Seasonal variation in value of per capita consumption of cow milk, butter, and cottage cheese, 2011, ETB

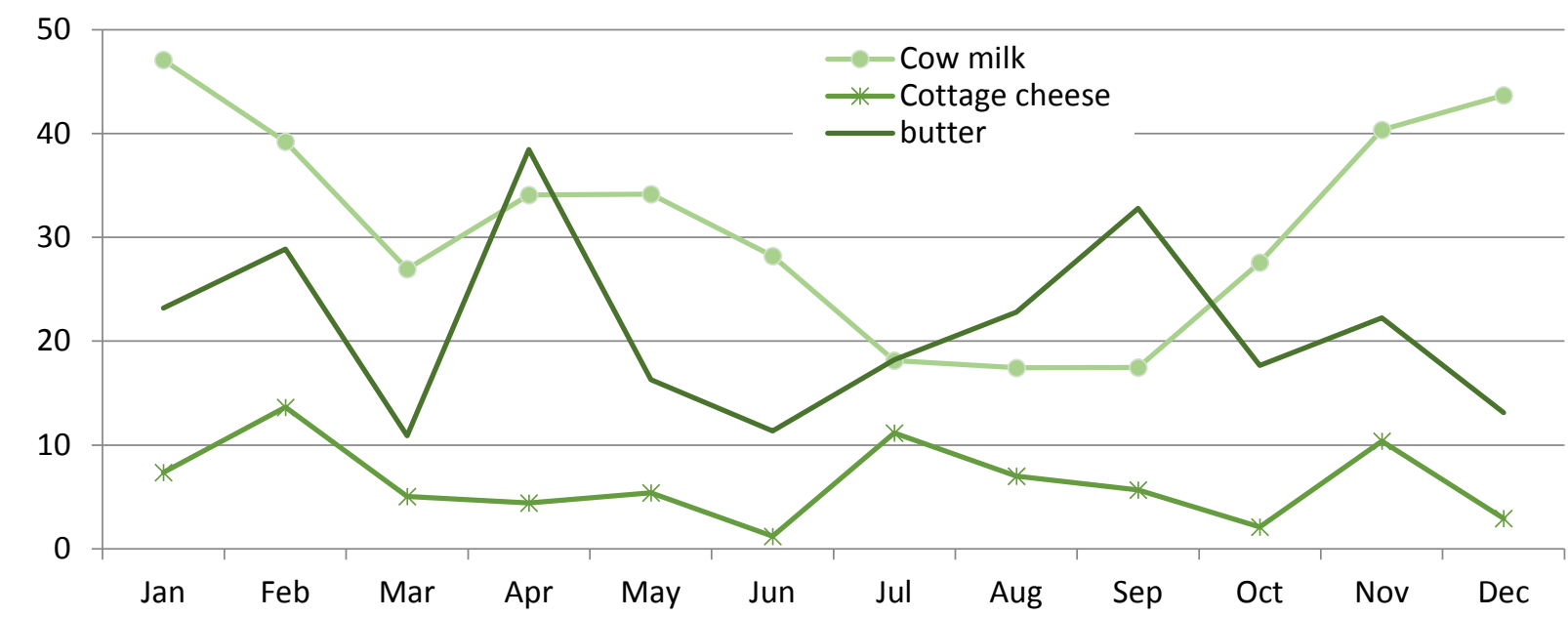

Source: Authors' calculation based on HICE, CSA

\section{THE ROLE OF INCOME AND PRICES IN ANIMAL-SOURCE FOOD CONSUMPTION}

\subsection{Descriptives on the consumption of animal-source food by quintiles of expenditure}

Significant research has been conducted in agricultural economics to understand the link between income and food consumption patterns. The parameters resulting from such research are important as they allow for economic modeling to assess the impacts of food policy changes on consumption, as well as projecting food requirements in the future, given reasonable assumptions on income growth. Researchers have also tried to improve their understanding of the transformation of food systems in economic development and associated changes in food consumption (e.g., Reardon and Timmer 2007). Several food consumption patterns can be distinguished with increasing income, including increased consumption of processed and ready-to-eat foods; the consumption of cereals becoming less important; and an increased share in the food basket for high-value crops, such as fruits and vegetables, dairy and animal products, and fish. Comparing the differences in consumption patterns between richer and poorer households often is indicative of how the transformation of food systems will shape food economies in a particular country. In an effort to understand these patterns in Ethiopia and see how ASF consumption differs over income levels, all households in the HICES survey of 2011 were ranked by wealth quintile. The shares of consumption of different food groups were then calculated. As expected, strong differences in the composition of consumption baskets are seen over poverty quintiles as well as over time (Subramanian and Deaton 1996; Bouis 1994; Bouis and Haddad 1992; Pingali 2007). Table 6.1 shows that, for any specific year, per capita ASF consumption of households in the richer quintiles are greater than for the poorer quintiles in all years. In 2010/11, households in the poorest quintile spent only 4.9 percent of their total food expenditures on ASFs, while households in the richest quintile spent 16.5 percent of total food expenditures on ASF, i.e., the rich spend more than three times more on ASF than the poor as a proportion of their food budget. 
Table 6.1. Animal-source food consumption expenditure per capita on and by food budget share, by quintiles of food consumption, 1996 to 2011

\begin{tabular}{lrrrr|rrrr}
\hline & $\mathbf{1 9 9 6}$ & $\mathbf{2 0 0 0}$ & $\mathbf{2 0 0 5}$ & $\mathbf{2 0 1 1}$ & $\mathbf{1 9 9 6}$ & $\mathbf{2 0 0 0}$ & $\mathbf{2 0 0 5}$ & $\mathbf{2 0 1 1}$ \\
& \multicolumn{2}{c}{ Consumption expenditures (ETB) } & \multicolumn{2}{c|}{ ASF share in food budget (\%) } \\
\hline Poorest quintile & 19.4 & 22.7 & 38.6 & 24.8 & 4.7 & 4.3 & 6.8 & 4.9 \\
Quintile 2 & 35.4 & 37.4 & 54.6 & 43.5 & 6.7 & 6.1 & 8.3 & 6.4 \\
Quintile 3 & 49.0 & 47.2 & 71.5 & 66.1 & 7.8 & 6.8 & 9.8 & 8.2 \\
Quintile 4 & 70.6 & 66.3 & 86.4 & 86.5 & 9.5 & 8.5 & 10.6 & 9.2 \\
Richest quintile & 127.5 & 129.5 & 129.1 & 224.6 & 12.5 & 12.7 & 13.1 & 16.5 \\
\hline Total & 69.8 & 70.0 & 85.1 & 104.4 & 9.7 & 9.1 & 10.7 & 11.2 \\
\hline
\end{tabular}

Source: Authors' calculation based on HICE, CSA

An important additional observation is that the mean per capita consumption distribution has changed across all quintiles over the years considered, signifying that overall ASF consumption expenditures increased for all income groups. In 1995/96, mean per capita consumption of households in the first and fifth quintile were ETB 19 and ETB 128, respectively. In 2010/11, these figures were ETB 25 and ETB 225, respectively for the same quintiles. Except for a modest increase in the food budget share for households in the fifth quintile, there is generally no dynamic in these food budget shares for other quintiles.

\subsection{Estimation method for the Quadratic Almost Ideal Demand System model}

So far we only have looked at descriptive evidence related to income changes and ASF consumption. This gives an incomplete picture. There have been significant methodological advances in the estimation of demand parameters linked to income over time. While demand for food items was previously analyzed in single-equation models, these estimates often led to inconsistencies in parameters when total food baskets were considered. To address this issue, a methodology called the Almost Ideal Demand Systems (AIDS) was developed. This method is widely used to estimate parameters as part of complete food demand systems (Deaton and Muellbauer 1980). The AIDS model is built on a utility maximization problem for a rational and representative household using an indirect utility function framework. The maximization problem relies on a set of important assumption and constraints. The model estimates simultaneous equations of budget shares by imposing important constrains, called the adding up, homogeneity, and symmetry restrictions, mathematically:

$$
\begin{aligned}
& \sum_{i=1}^{n} \alpha_{i}=1 ; \sum_{i=1, j=1}^{n} \gamma_{i j}=0 ; \sum_{i=1}^{n} \beta_{j}=0 ; \sum_{i} \lambda_{i}=0 \\
& \sum_{j} \gamma_{i j}=\mathbf{O} \\
& \gamma_{i j}=\gamma_{j i}
\end{aligned}
$$

We build on this framework. However, in estimating the Engle curve, unlike in the original Almost Ideal Demand System (AIDS), we rely on an alternative method suggested by Banks, Blundell, and Lewbel (1997), the Quadratic Almost Ideal Demand System (QUAIDS). This is a slightly modified version of the AIDS model that includes a quadratic income/expenditure term to account for a non-linear approximation. The estimated QUAIDS equation, with the definitions of price indices, is given by:

$$
\begin{gathered}
w_{i h}=\alpha_{i}+\sum_{j=1}^{n} \gamma_{i j} \ln p_{j}+\beta_{i} \ln \left[\frac{x_{h}}{a(p)}\right]+\frac{\lambda_{i}}{b(p)}\left\{\ln \left[\frac{x_{h}}{a(p)}\right]\right\}^{2} \\
\ln a(p)=\alpha_{0}+\sum_{k=1}^{n} \alpha_{k} \ln p_{k}+\frac{1}{2} \sum_{k=1}^{n} \sum_{j=1}^{n} \gamma_{k j} \ln p_{k} \ln p_{j} \\
b(p)=\prod_{k=1}^{n} p_{k=1}^{\beta_{k}}
\end{gathered}
$$


We further rely on Shonkwiler and Yen (1999)'s two step estimation method, which accounts for the problem of zero expenditures. Our estimation method deals with the problem of endogeneity and accounts for spatial variation and for differences in demographic structure. The dichotomous equation of zeroexpenditure budget share is stated as follows.

$$
\begin{gathered}
w_{i k}^{*}=f\left(x_{i h, \mu} \mu\right)+\mu_{i h}, d_{i h}^{*}=z_{i h}^{\prime} \theta_{i}+v_{i h} \\
d_{i h}=\left\{\begin{array}{l}
1 \ldots \ldots \ldots i f \ldots d_{i h}^{*}>0 \\
0 \ldots \ldots \ldots i f \ldots d_{i h}^{*} \leq 0
\end{array}\right. \\
w_{i h}=d_{i h} w_{i h}^{*} \\
E\left(w_{i h} \mid x_{i h}, z_{i h}\right)=\Phi\left(z_{i h}^{\prime} \theta_{i}\right) f\left(x_{i h}, \mu_{i}\right)+\delta_{i} \phi\left(z_{i h}^{\prime} \theta_{i}\right) \\
w_{i k}=\Phi\left(z_{i h}^{\prime} \theta_{i}\right) f\left(x_{i h}, \mu_{i}\right)+\delta \phi\left(z_{i h}^{\prime} \theta\right)+e_{i h}
\end{gathered}
$$

It is to be noted that we applied the same estimation methods as discussed in detail in the study by Tafere and Worku (2012).

\subsection{Results of the Quadratic Almost Ideal Demand System model}

Table 6.2 presents the results of these estimation methods using the HICES of $2011 .{ }^{4}$ The expenditure elasticity estimates for beef are estimated to be $0.456,0.684$ and 0.108 at the national level, and for urban and rural areas respectively. ${ }^{5 / 6}$ In contrast with beef, mutton and goat have higher income elasticities for all settings, i.e., at the national level as well as in urban and rural areas. This could be due partly to the more divisible nature of these types of animal-soured foods than for beef.

Table 6.2. Expenditure elasticities estimates for animal-source food groups

\begin{tabular}{lccc}
\hline & National & Urban & Rural \\
\hline Beef & $0.465^{\star \star \star}$ & $0.684^{\star \star \star}$ & $0.108^{\star \star \star}$ \\
& {$[0.0249]$} & {$[0.0258]$} & {$[0.0966]$} \\
Mutton \& goat & $2.702^{\star \star *}$ & $1.951^{\star \star \star}$ & $0.647^{\star \star \star}$ \\
Other meat \& animal products & $0.479^{\star \star \star}$ & $0.602^{\star \star \star}$ & $-0.603^{\star \star \star}$ \\
& {$[0.1041]$} & {$[0.1168]$} & {$[0.2462]$} \\
Dairy products & $0.511^{\star \star *}$ & $0.379^{\star \star \star}$ & $1.010^{\star \star \star}$ \\
& {$[0.0198]$} & {$[0.0205]$} & {$[0.0446]$} \\
\hline
\end{tabular}

Source: Authors' calculation based on HICE, CSA.

Note: Values in brackets are standard errors for the elasticities. ${ }^{*}, * *$ and $* * *$ represent $1 \%, 5 \%$ and $10 \%$ significance level

The expenditure elasticity for 'Other meat \& animal products' - including poultry - in the national and urban setting is found to be almost similar to beef. A striking result is that we find a negative income

\footnotetext{
${ }^{4} \mathrm{~A}$ relevant feature of the previous study by Tafere and Worku (2012) was that the external retail price was used to estimate the elasticities. However, in this study, the estimates from unit values seem to be consistent with the theoretical restrictions. Kedir (2001) and Girma and Kedir (2002) underlined the shortcomings of estimating models using unit values. Previous studies on demand estimation by Tafere et al. (2010) and Tafere and Worku (2012) used external retail prices. In this study, we attempted to estimate using external prices. However, we come up with estimates that are sharply inconsistent with theoretical projections. As a result, we resorted to the unit value estimations. We found theoretically consistent estimates as well as coefficients that are close to the estimated demand estimates of the aforementioned studies.

${ }^{5}$ In the previous study by Tafere and Worku (2012), the estimated expenditure/income elasticity coefficients, beef for instance, was $0.939,0.896$, and 0.985 for national, urban and rural settings, respectively.

${ }^{6}$ The estimated elasticity using the external price for beef was almost the same as that of the unit price. In this study in which unit values were used, we find relatively lower magnitudes of expenditure estimates for beef.
} 
elasticity (0.603) for rural households in this category, indicating the 'Other meat \& animal products' category to be inferior for these households. This might be explained by a number of reasons. First, the 'Other meat \& animal products' category consists of internal organs (liver, kidney, tripe) of animals, as well as wild animal and bird meat (including poultry) and fish. These latter meat and fish products have a very small share (about 500 observations from 500,000 total food item lines). Internal organs are mostly considered inferior goods as food. On the other hand, there are some meats within the category that are more preferred, such as dulet ${ }^{71}$, which is now as expensive as other meat. The same argument on preferred foods also holds for fish. But since we have very few observations for these products, it will not have reversed the sign of the estimated elasticities.

Having a higher income elasticity for mutton and goat implies that households tend to spend a higher share of any incremental income on such livestock products than on dairy products. ${ }^{8}$ Except for the 'Other meat \& animal products' group, the expenditure elasticity for all livestock products is higher in rural than in urban areas. The perishable nature of the products, and poorer rural transport infrastructure and market interlinkages have been suggested as explanations for why higher income responses in the consumption of AFS are seen for households in rural areas. Moreover, it has been shown that income elasticities are higher in areas that are poorer, such as rural areas (Bouis and Haddad 1992).

\footnotetext{
${ }^{7}$ Most commonly consumed animal organ food.

${ }^{8}$ A similar pattern was observed by Tafere and Worku (2012) using 2005 data. However, in our estimates the gap between dairy products and beef in response to income changes has narrowed, whereas, this gap has widened in relation to mutton and goat.
} 
Table 6.3. Compensated price elasticity estimates for animal-source food groups

\begin{tabular}{|c|c|c|c|c|c|}
\hline & & Beef & $\begin{array}{l}\text { Mutton \& } \\
\text { goat }\end{array}$ & $\begin{array}{l}\text { Other meat } \\
\& \text { animal } \\
\text { products }\end{array}$ & $\begin{array}{l}\text { Dairy } \\
\text { products }\end{array}$ \\
\hline \multirow[t]{6}{*}{ Beef } & National & $-0.727^{\star \star \star}$ & $0.094^{\star \star \star}$ & $0.303^{\star \star \star}$ & $0.330^{\star \star \star}$ \\
\hline & & [0.0314] & [0.0233] & [0.0246] & [0.0174] \\
\hline & Urban & $-0.538^{\star * \star}$ & $0.097^{\star \star *}$ & $0.127^{\star \star \star}$ & $0.314^{\star * *}$ \\
\hline & & [0.0302] & [0.0216] & {$[0.0260]$} & [0.0162] \\
\hline & Rural & $-0.742^{\star \star \star}$ & $-0.009^{\star \star \star}$ & $0.631^{\star \star \star}$ & $0.121^{\star \star \star}$ \\
\hline & & [0.1048] & [0.1007] & {$[0.0716]$} & {$[0.0737]$} \\
\hline \multirow[t]{6}{*}{ Mutton \& goat } & National & $-1.018^{\star \star \star}$ & $-0.116^{\star \star \star}$ & 0.369 & $0.766^{\star}$ \\
\hline & & [0.0916] & [0.1581] & [0.1036] & [0.1198] \\
\hline & Urban & $-0.346^{\star \star \star}$ & $-0.896^{\star \star \star}$ & 0.170 & $1.072^{*}$ \\
\hline & & [0.1234] & [0.1597] & [0.1030] & [0.0855] \\
\hline & Rural & $-1.158^{\star \star \star}$ & $-1.257^{\star \star \star}$ & 1.074 & $1.342^{*}$ \\
\hline & & [0.6657] & [1.022] & [0.5366] & [0.6173] \\
\hline \multirow{6}{*}{$\begin{array}{l}\text { Other meat \& } \\
\text { animal products }\end{array}$} & National & $1.307^{\star \star \star}$ & $0.371^{\star \star \star}$ & 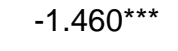 & 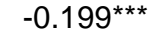 \\
\hline & & [0.0796] & [0.084] & {$[0.0670]$} & [0.0980] \\
\hline & Urban & $0.573^{\star \star \star}$ & $0.319 * \star \star$ & $-0.888^{\star \star \star}$ & $0.015^{\star \star \star}$ \\
\hline & & [0.1321] & [0.1065] & [0.1203] & [0.0725] \\
\hline & Rural & $1.791^{\star * *}$ & $0.918^{\star \star \star}$ & $-1.562^{\star \star \star}$ & $-0.957^{\star \star \star *}$ \\
\hline & & {$[0.2477]$} & [0.2399] & [0.1965] & [0.1657] \\
\hline \multirow[t]{6}{*}{ Dairy products } & National & $0.523^{\star \star \star}$ & $-0.163^{\star \star \star}$ & $0.055^{\star \star \star}$ & $-0.450^{\star \star \star}$ \\
\hline & & [0.0214] & [0.0329] & [0.0200] & [0.0170] \\
\hline & Urban & $0.708^{\star \star \star}$ & $0.089 * \star \star$ & $0.106^{\star \star \star}$ & $-1.135^{\star \star \star}$ \\
\hline & & [0.0479] & [0.0603] & [0.0345] & [0.0557] \\
\hline & Rural & $0.052^{\star \star \star}$ & $-0.058^{\star \star \star}$ & $-0.044^{\star \star \star}$ & $-0.007^{\star \star \star}$ \\
\hline & & [0.0670] & [0.0824] & [0.0479] & [0.0201] \\
\hline
\end{tabular}

Source: Authors' calculation based on HICE, CSA.

Note: Values in brackets are standard errors for the elasticities. * ${ }^{* *}$ and $* * *$ represent $1 \%, 5 \%$ and $10 \%$ significance level

Compensated price elasticities of ASF are presented in Table 6.3. The diagonal elements in the table represent the own price elasticities of the four categories of ASF. We find statistically significant and negative price elasticity estimates for all products, a result that is consistent with our theoretical expectations. ${ }^{9}$ Values range from -1.562 for "Other meat \& animal products" (including poultry) in rural areas to -0.007 for dairy products in rural areas. In contrast, in urban areas mutton and goat have relatively higher own price elasticity than the other categories.

Table 6.3 also presents a summary of cross-price elasticities. Except for mutton and goat, in most instances, the cross-price elasticities are found to be positive, suggesting that there is a high degree of substitutability among many pairs. We also see that there is degree of complementary between dairy products and mutton and goat and to a lesser extent with dairy products in rural areas, as we find there negative estimated cross-price elasticities.

\subsection{Simulations of future demand and of commercial market development}

We use the estimated elasticity estimates to evaluate how demand for ASF products might evolve in the future. We do so by integrating expected population dynamics, differentiating between urban and rural areas, relying on population projections by the World Bank. We further assume a uniform annual income growth of 3 percent and no real price increases. Figure 6.1 shows under these assumptions the evolution in

\footnotetext{
${ }^{9}$ In almost all of the commodity classifications, the estimates have been found to be close to the elasticity estimates of the 2005 data by Tafere and Worku (2012).
} 
demand for ASF for rural and urban areas and for different categories of ASF. The results show that the demand for ASF will increase by 165 percent between 2011 and 2030. We see especially rapid growth in urban demand for ASF. While urban consumption of ASF made up 30 percent of total ASF consumption in 2011, this is expected to increase to 46 percent in 2030. We also assess demand for different categories of ASF. We see a rapid expansion of mutton and goat consumption. While this category made up 17 percent of the ASF consumption in 2011, this is expected to increase to 34 percent in 2030.

Figure 6.1. Evolution of future demand for animal-source food

25

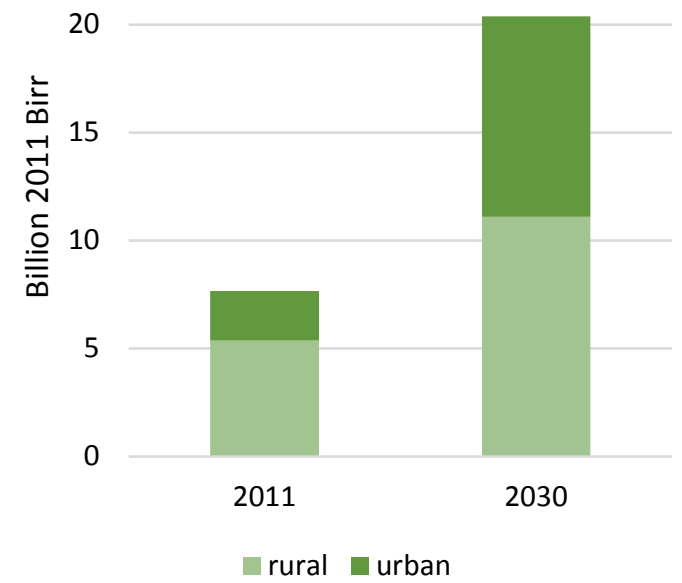

25

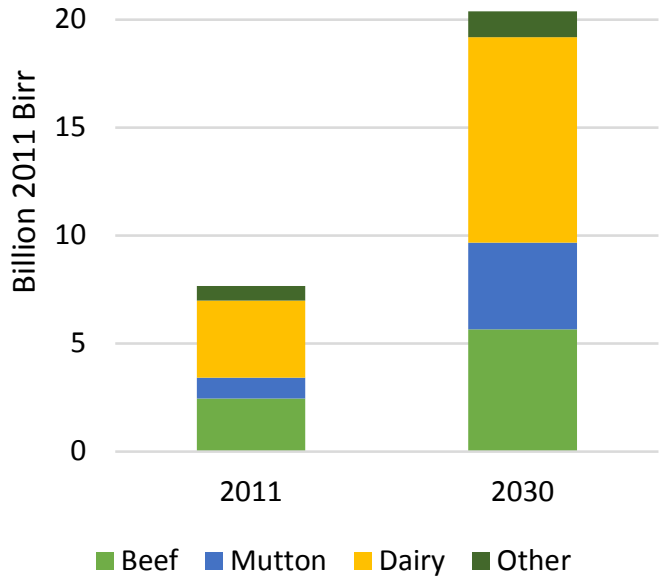

Source: Authors' calculation based on HICE, CSA

Next, we look at the development of commercial markets for local consumption. In this case, we assume the same use of commercial markets in urban areas as in the past, but we assume an increase in market use in rural areas over time by 20 percent for dairy products, mutton and goat, and other animal products an increase that is partly driven by improved rural infrastructure in the future given the government's large investments in this area. Figure 6.2 shows the results of these simulations. The results illustrate the rapid growth in urban markets as commercial urban ASF demand will increase by 304 percent compared to the situation in 2011. While the share of urban markets made up 46 percent of the commercial value of ASF in 2011 , this is expected to increase to 64 percent of the nation-wide value of commercial markets. These data indicate to what the extent the rural-urban ASF value chains will grow in the future. Rural commercial markets are expected to grow by 94 percent. Overall, a growth of 192 percent is expected by 2030 . This growth will have enormous implications for different agents involved in these markets, such as traders, transporters, wholesalers, retailers, butchers, and slaughterhouses, with these numbers expected to increase rapidly in the future. 
Figure 6.2. Evolution of commercial market development for animal-source food
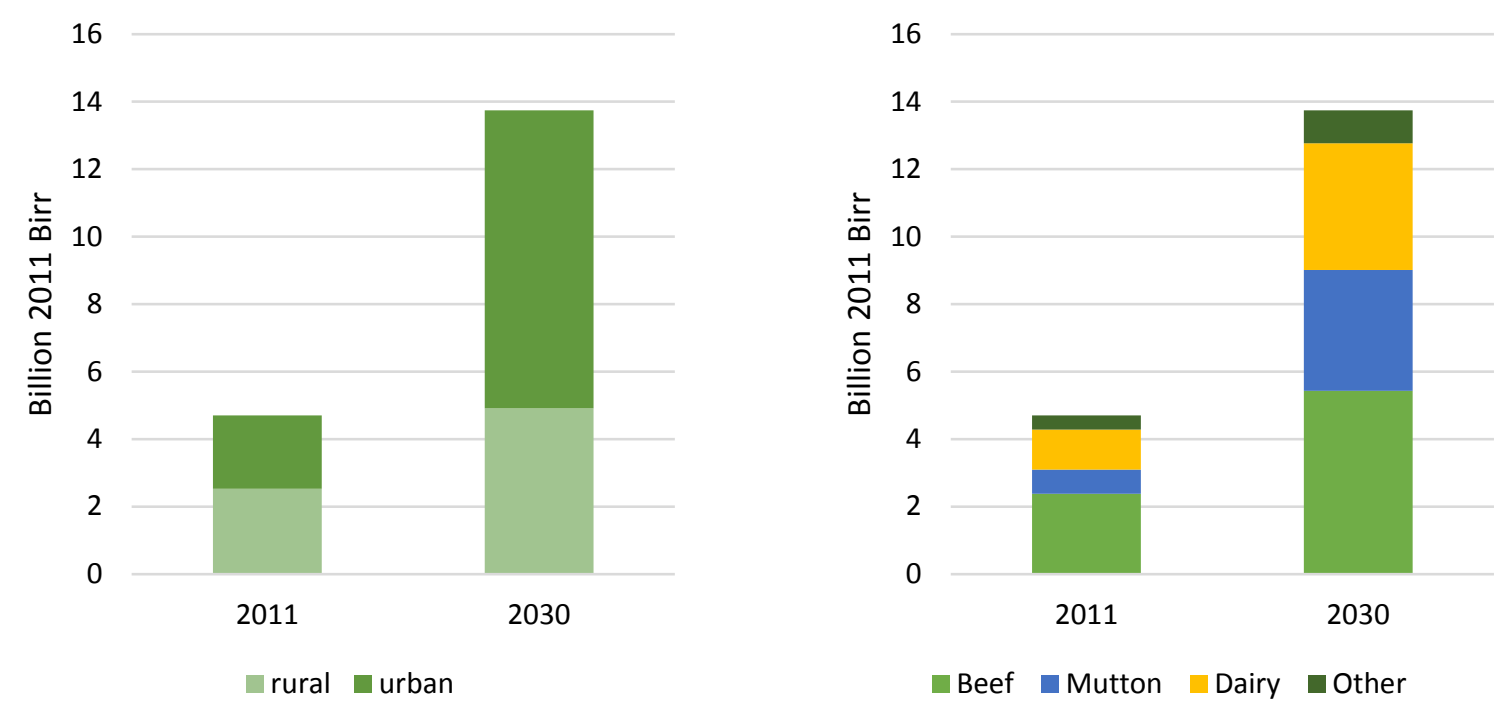

Source: Authors' calculation based on HICE, CSA

\section{CONCLUSION AND IMPLICATIONS}

Using unique nationally representative household consumption data sets that extend from 1995/96 to 2010/11, this study looks at patterns and changes in ASF consumption and attempts to identify some of the drivers of these dynamics. We further assess future demand in overall ASF consumption as well as for commercial market development.

We find overall that Ethiopian diets are dominated by grains and that both per capita consumption and food budget shares of ASF are low. However, real expenditures on ASF have increased by 50 percent over the 15-year period from 2006 to 2011. However, although the quantity of ASF consumed increased, this increase was significantly less than for expenditures on ASF because of relatively higher price increases of ASF over this period. When we split up expenditures by ASF categories, we show that expenses on dairy products make up almost half of all the ASF expenditures. We further find that the share of ASF expenditures in total food for the richest quintile is three times higher than for the poorest quintile and that residents in urban areas spend twice as much on ASF per capita than in rural areas. We also show a rapid increase of consumption in milk powder, especially in urban areas and pastoralist zones. Finally, we show that there is significant variation over the year in consumption, seemingly associated with religious customs.

We rely on a QUAIDS model to estimate price and income elasticities. ${ }^{10}$ Most livestock products have positive cross-price elasticities, indicating that there are significant substitution possibilities between different types of ASF. Price elasticity estimates are found to be higher in rural areas than in urban areas, which was expected as these areas are often poorer. We use the elasticities to evaluate future demand for ASF products in the country. Under reasonable assumptions of urbanization and income growth, we estimate that the demand for ASF will increase very fast between 2011 and 2030, increasing by

\footnotetext{
${ }^{10}$ We find slightly lower magnitudes of elasticities than in older studies, possibly due to the fact that the data were collected over an extended period of 12 months. One important aspect that is worth mentioning is that zero expenditures became much more prevalent than in the 2005 data, leading to more households with zero budget share for this product. Zero expenditure shares might have been driven by extended periods of fasting seasons by orthodox Christians in the 12-months data collection period, which was not the case in 2005 data.
} 
165 percent. The simulation results further illustrate the rapid growth in urban markets. Commercial ASF demand will almost triple between 2011 and 2030. This growth will have enormous implications for agents involved in these markets and value chains, such as input and output traders, transporters, wholesalers, retailers, butchers, and slaughterhouses.

The expected expansion of ASF demand is likely to lead to improved health and nutritional outcomes in Ethiopia. However, to assure that this increased local demand can be met by local supply and not by imports, more attention will need to be paid to livestock-related investments, including increased adoption of improved animal husbandry practices, such as the adoption of cross-bred cows, appropriate veterinary health practices, and improved feeding, and the facilitation of an enabling environment that will allow for efficient livestock markets. Additional efforts towards behavior change communication will be needed to assure that increased consumption of ASF can play a beneficial role towards improved nutritional outcomes in the country. 


\section{REFERENCES}

Bachewe, F. N., B. Minten, and F. Yimer. 2017. The rising costs of animal-source foods in Ethiopia: Evidence and implications. ESSP Discussion Paper 108. International Food Policy Research Institute and Ethiopia Development Research Institute. Addis Ababa.

Banks, J., R. Blundell, and A. Lewbel. 1997. "Quadratic Engel curves and consumer demand." The Review of Economics and Statistics 79 (4): 527-539.

Bennett, M.K., 1941. "International contrasts in food consumption." Geographic Review. 31(3), 365-376.

Bouis, H.E., and L.J. Haddad. 1992. "Are estimates of calorie-income elasticities too high?: A recalibration of the plausible range." Journal of Development Economics 39 (2): 333-364.

Bouis, H.E. 1994. "The effect of income on demand for food in poor countries: Are our food consumption databases giving us reliable estimates?" Journal of Development Economics 44 (1): 199-226.

CSA (Central Statistical Office). 2011. Household Income and Consumption Expenditure Survey. Federal Democratic Republic of Ethiopia, Addis Ababa.

CSA (Central Statistical Office). 1996. Household Income and Consumption Expenditure Survey. Federal Democratic Republic of Ethiopia, Addis Ababa.

CSA (Central Statistical Office). 2000. Household Income and Consumption Expenditure Survey. Federal Democratic Republic of Ethiopia, Addis Ababa.

CSA (Central Statistical Office). 2005. Household Income and Consumption Expenditure Survey. Federal Democratic Republic of Ethiopia, Addis Ababa.

CSA (Central Statistical Office). 2012. Welfare Monitoring Survey 2011. Indicators on Living Standard, Accessibility and Household Assets. Federal Democratic Republic of Ethiopia, Addis Ababa.

CSA (Central Statistical Office). 2017a. Country and Regional Level Consumer Price Indices. Federal Democratic Republic of Ethiopia, Addis Ababa.

CSA (Central Statistical Office). 2017b. Consumer Price Survey. Federal Democratic Republic of Ethiopia, Addis Ababa.

CSA (Central Statistical Office). 2017c. Producer Price Survey. Federal Democratic Republic of Ethiopia, Addis Ababa.

Deaton, A. and J. Muellbauer. 1980. "An almost ideal demand system." The American Economic Review 70 (3): $312-$ 326.

Diao, X., D. Headey, and M. Johnson. 2008. "Toward a green revolution in Africa: What would it achieve, and what would it require?" Agricultural Economics 39: 539-550.

Farmer, E. 2010. End market analysis of Ethiopian livestock and meat. microREPORT \#164, prepared for USAID, http://www.valuechains.org/dyn/bds/docs/801/USAID\%20Ethiopia\%20Livestock\%20End\%20Market\%20Study.pdf.

FVI-Idele (France Vétérinaire Internationale - Institute de l'Elevage). 2016. Complementary feasibility study for the relocation and modernization of Addis Ababa Abattoirs. Study prepared for Addis Ababa Abattoirs Enterprise (AAAE). Paris, France.

Food and Agriculture Organization. 2016. OECD-FAO Agricultural Outlook 2016-2025. Special Focus: Sub-Saharan Africa. Available at: https://doi.org/10.1787/agr_outlook-2016-en.

Girma, S. and A.M. Kedir. 2002. When does food stop being a luxury? Evidence from quadratic Engel curves with measurement error. CREDIT Research Paper No. 02/03.

Gordon, A., S.D. Tegegne, and M. Tadesse. 2007. Marketing systems for fish from Lake Tana, Ethiopia: Opportunities for improved marketing and livelihoods. IPMS (Improving Productivity and Market Success) of Ethiopian Farmers Project Working Paper 2. ILRI, Nairobi.

Hoddinott, J., D. Headey, and M. Dereje. 2015. "Cows, missing milk markets, and nutrition in rural Ethiopia." Journal of Development Studies 51 (8): 958-75.

Humphries, D.L., J.R. Behrman, B.T. Crookston, K.A. Dearden, W. Schott, and M.E. Penny. 2014. "Households Across All Income Quintiles, Especially the Poorest, Increased Animal Source Food Expenditures Substantially during Recent Peruvian Economic Growth." PLoS One 9(11): p.e110961.

Jayne, T., G. Anriquez, and E. Collier. 2013. African agriculture toward 2030: changes in urbanization and agricultural land dynamics and their implications for CGIAR research. In Independent Science and Partnership Council (ISPC) Foresight meeting. 
Kedir, A.M. 2001. Some issues in using unit values as prices in the estimation of own-price elasticities: Evidence from urban Ethiopia. CREDIT Research Paper No. 01/11.

Leroy, J.L. and E.A. Frongillo. 2007. “Can interventions to promote animal production ameliorate undernutrition?” The Journal of Nutrition 137 (10): 2311-2316.

Mclntire, J., D. Bourzat, and P. Pingali. 2016. Crop-livestock interaction in sub-Saharan Africa. Washington, DC: World Bank.

Neumann, C., D.M. Harris, and L.M. Rogers. 2002. "Contribution of Animal Source Foods in Improving Diet Quality and Function in Children in the Developing World." Nutrition Research 22 (1-2): 193-220.

Pingali, P. 2007. "Westernization of Asian diets and the transformation of food systems: implications for research and policy." Food Policy 32 (3): 281-298.

Randolph, T.F., E. Schelling, D. Grace, C.F. Nicholson, J.L. Leroy, D.C. Cole, M.W. Demment, et al. 2007. Role of livestock in human nutrition and health for poverty reduction in developing countries. Journal of Animal Science 85(11): 2788-2800.

Reardon, T., and C.P. Timmer. 2007. "Transformation of Markets for Agricultural Output in Developing Countries since 1950: How Has Thinking Changed?" In Handbook of Agricultural Economics. Vol.3, edited by R. E. Evenson and P. Pingali, 2808-2855. Amsterdam: Elsevier Press.

Sadler, K., and A. Catley. 2009. Milk Matters: The role and value of milk in the diets of Somali pastoralist children in Liben and Shinile, Ethiopia. Feinstein International Center, Tufts University and Save the Children, Addis Ababa

Shonkwiler, J.S. and Yen, S.T., 1999. "Two-step estimation of a censored system of equations." American Journal of Agricultural Economics 81 (4): 972-982.

Sibhatu, K. T. and M. Qaim. 2017. "Rural food security, subsistence agriculture, and seasonality." PloS ONE 12 (10): 0186406.

Speedy, A.W. 2003. "Animal Source Foods to Improve Micronutrient Nutrition and Human Function in Developing Countries: Global Production and Consumption of Animal Source Foods." The Journal of Nutrition 133:3965-71.

Stifel, D., Woldehanna, T., 2014. Utility-consistent poverty in Ethiopia, 2000-11: Welfare improvements in a changing economic landscape. WIDER Working Paper 2014/125.

Subramanian, S., and A. Deaton. 1996. "The demand for food and calories." Journal of Political Economy 133-162.

Tafere, K., A.S. Taffesse, S. Tamiru, N. Tefera, and Z. Paulos. 2010. Food demand elasticities in Ethiopia: Estimates using household income consumption expenditure (HICE) survey data. ESSP Discussion Paper 11. International Food Policy Research Institute and Ethiopian Development Research Institute. Addis Ababa.

Tafere, K., and I. Worku. 2012. Consumption Patterns of Livestock Products in Ethiopia: Elasticity Estimates Using HICES (2004/05) Data. Development Strategy and Governance Division, International Food Policy Research InstituteEthiopia Strategy Support Program II. Addis Ababa, Ethiopia: Ethiopian Development Research Institute.

Tefera, T.L., R. Puskur, D. Hoekstra, and A. Tegegne. 2010. Commercializing dairy and forage systems in Ethiopia: An innovation systems perspective. ILRI Working Paper 17, Nairobi.

Tegegne, A., B. Gebremedhin, D. Hoekstra, B. Belay, and Y. Mekasha. 2013. Smallholder dairy production and marketing systems in Ethiopia: IPMS experiences and opportunities for market-oriented development. IPMS (Improving Productivity and Market Success) of Ethiopian Farmers Project Working Paper 31. ILRI, Nairobi.

Workicho, A., T. Belachew, G.T. Feyissa, B. Wondafrash, C. Lachat, R. Verstraeten, and P. Kolsteren. 2016. “Household Dietary Diversity and Animal Source Food Consumption in Ethiopia: Evidence from the 2011 Welfare Monitoring Survey." BMC Public Health 16 (1). BMC Public Health:1192.

Worku, I., M. Dereje, B. Minten, and K. Hirvonen. 2016. Diet Transformation in Africa: The Case of Ethiopia. Development Strategy and Governance Division, International Food Policy Research Institute-Ethiopia Strategy Support Program II. Addis Ababa, Ethiopia: Ethiopian Development Research Institute.

World Bank. 2014. Ethiopia: Poverty Assessment. Report No. AUS6744. Poverty Global Practice. Africa Region. World Bank Group, Washington, DC.

Zaida, H., J. Perez-Formigo, L. Sordo, E. Gadisa, J. Moreno, A. Benito, A. Aseffa, and E. Custodio. 2015. "Low Dietary Diversity and Intake of Animal Source Foods among School Aged Children in Libo Kemkem and Fogera Districts, Ethiopia." PLoS ONE 10 (7): 1-18.

Zhang, Z., P.D. Goldsmith, and A. Winter-Nelson. 2016. "The Importance of Animal Source Foods for Nutrient Sufficiency in the Developing World: The Zambia Scenario." Food and Nutrition Bulletin. 37 (3):303-316. 


\section{ANNEXES}

\section{Annex 1: Data and sampling issues for the QUAIDS demand analysis}

To estimate the income and price elasticities, we use the 2010/11 household consumption and welfare monitoring and retail price surveys of the CSA. There are changes in sampling and sampling weights compared to the survey that was conducted in 2005, which might explain some of the differences with Tafere and Worku (2012).

First, the CSA previously collected a relatively higher number of observations in rural areas and fewer in urban centers. For the 2011 survey, this set-up changed. Second, CSA introduced a slightly different data collection procedure. Previously CSA collected data in two seasons, i.e. the lean and harvest seasons. In 2011 , CSA collected data continuously over a 12-month period. Because of widely observed Orthodox religion fasting with regards to animal-source food, such an approach might have led to a decline in the reporting of the consumption of livestock and livestock products, assuming that the lean and harvest periods fell outside the major fasting periods, which we believe to be the case. This seems to explain the large number of observations of zero consumption of ASF compared to 2005. In particular, from all the 21,950 surveyed households in 2005, 18,939 reported that they had consumed at least one ASF. In 2011, of the 27,835 households surveyed, only 16,330 households reported that they had consumed or used one of the livestock products. While the adjustment in sampling weight partly attenuates the problem in zero expenditure, it is to be noted that having more zero expenditures coupled with Orthodox religion fasting might have implications on the estimated elasticities for the period 2011.

\section{Annex 2: Animal-source food consumption and socio-economic indicators}

We look at differences in ASF consumption with respect to socio-economic indicators along two dimensions, gender of the head of the household and employment status of the head of the household.

Table A1 shows how the consumption of ASF differs by the gender of the head of household. As we did not have information on the head of households for the whole sample, the share of ASF differs slightly from previous tables. Overall, we find that that the share of ASF is slightly lower for female-headed households compared to male-headed ones, especially in most recent years. While male-headed households allocate about 11.3 percent of their food expenditures to ASF in 2011, this was slightly lower for female-headed households at 11.0 percent.

Table A1: Female and male-headed households, animal-source food as a percentage share of total food consumption

\begin{tabular}{lrrr}
\hline & $\mathbf{1 9 9 6}$ & $\mathbf{2 0 0 5}$ & $\mathbf{2 0 1 1}$ \\
\hline Male headed & 9.5 & 11.0 & 11.3 \\
Female headed & 9.7 & 9.7 & 11.0 \\
Total & 9.6 & 10.8 & 11.2 \\
\hline
\end{tabular}

Source: Source: Authors' calculation based on HICE and WMS, CSA

Table A2 further presents per capita consumption of ASFs across households with different employment status. The results in the table illustrate how consumption is especially low for those that are employed as family workers. This likely reflects the effects of low income that we discuss in more detail in the main text. 
Table A2: Employment status, animal-source food as a percentage share of total food consumption, by sex of household head

\begin{tabular}{|c|c|c|c|c|c|c|}
\hline & \multicolumn{3}{|c|}{2005} & \multicolumn{3}{|c|}{2011} \\
\hline & Male & Female & Total & Male & Female & Total \\
\hline Employer & 12.4 & 13.3 & 12.5 & 18.3 & 14.7 & 17.8 \\
\hline Self-employed, formal or informal sectors & 10.3 & 8.8 & 10.1 & 10.8 & 10.7 & 10.7 \\
\hline Employed in private enterprise, formal or informal sectors & 13.4 & 9.9 & 12.9 & 12.7 & 12.6 & 12.7 \\
\hline Employed in public office & 17.7 & 15.9 & 17.4 & 15.5 & 14.8 & 15.4 \\
\hline Employed by NGO & 17.3 & 15.8 & 17.1 & 17.8 & 17.9 & 17.8 \\
\hline Employed in domestic work & 5.9 & 7.6 & 6.7 & 10.4 & 7.9 & 9.5 \\
\hline Unpaid family worker & 6.1 & 10.3 & 7.3 & 12.0 & 16.4 & 14.0 \\
\hline Other & 12.3 & 3.2 & 10.5 & 14.7 & 6.6 & 10.5 \\
\hline Total & 11.0 & 9.6 & 10.8 & 11.4 & 11.3 & 11.4 \\
\hline
\end{tabular}


Getachew Ahmed Abegaz is a Research Officer in the Ethiopia Strategy Support Program (ESSP), a joint program of the International Food Policy Research Institute and the Ethiopian Development Research Institute, based in Addis Ababa, Ethiopia; Ibrahim Worku Hassen is an MSc student at the Harvard Kennedy School, Cambridge, Massachusetts, USA; and Bart Minten is Program Leader and Senior Research Fellow in the Ethiopia Strategy Support Program in the Development Strategy and Governance Division of IFPRI based in Addis Ababa.

\section{Acknowledgments}

This paper is made possible by the support of the American people provided to the Feed the Future Innovation Lab for Livestock Systems (LSIL), Institute of Food and Agricultural Sciences, University of Florida in partnership with the International Livestock Research Institute (ILRI). LSIL is funded by the United States Agency for International Development (USAID) through a five-year Leader with Associates Cooperative Agreement Award No. AID-OAA-L-15-00003.

\section{About ESSP}

The Ethiopia Strategy Support Program is an initiative to strengthen evidence-based policymaking in Ethiopia in the areas of rural and agricultural development. Facilitated by the International Food Policy Research Institute (IFPRI), ESSP works closely with the government of Ethiopia, the Ethiopian Development Research Institute (EDRI), and other development partners to provide information relevant for the design and implementation of Ethiopia's agricultural and rural development strategies. For more information, see http://www.ifpri.org/book-757/ourwork/program/ethiopia-strategy-support-program; http://essp.ifpri.info/; or http://www.edri-eth.org/.

The ESSP Working Papers contain preliminary material and research results from IFPRI and/or its partners in Ethiopia. The papers are not subject to a formal peer review. They are circulated to stimulate discussion and critical comment.

INTERNATIONAL FOOD POLICY RESEARCH INSTITUTE 1201 Eye Street, NW | Washington, DC 20005-3915 USA $\mathrm{T}:+1.202 .862 .5600 \mid \mathrm{F}:+1.202 .862 .5606$ Email: ifpri@cgiar.org | www.ifpri.org

IFPRI-ESSP ADDIS ABABA

P.O. Box 5689, Addis Ababa, Ethiopia

$\mathrm{T}:+251.11 .617 .2000 \mid \mathrm{F}:+251.11 .646 .2318$

mahlet.mekuria@cgiar.org | http://essp.ifpri.info
ETHIOPIAN DEVELOPMENT RESEARCH INSTITUTE

P.O. Box 2479, Addis Ababa, Ethiopia

T: +251.11.550.6066; +251.11.553.8633 | F: +251.11.550.5588

info@edri-eth.org | www.edri-eth.org

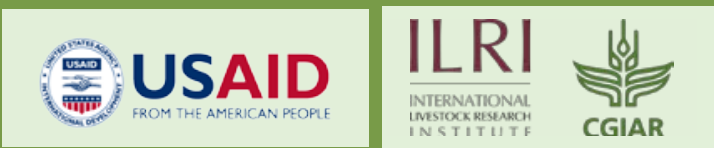

UF|IFAS

UNIVERSITY of FLORIDA

The Ethiopia Strategy Support Program (ESSP) is managed by the International Food Policy Research Institute (IFPRI) and is financially supported by the United States Agency for International Development (USAID), the Department for International Development (DFID) of the government of the United Kingdom, and the European Union. The research presented here was conducted as part of the CGIAR Research Program on Policies, Institutions, and Markets (PIM), which is led by IFPRI. This publication has been prepared as an output of ESSP and has not been independently peer reviewed. Any opinions expressed here belong to the author(s) and do not necessarily reflect those of IFPRI, the Ethiopian Development Research Institute, USAID, DFID, the European Union, PIM, or CGIAR.

Copyright @ 2018, Remains with the author(s). All rights reserved. 